\title{
Analysis of Rab protein function in neurotransmitter receptor trafficking at hippocampal synapses
}

Nashaat Z. Gerges ${ }^{1}$, Tyler C. Brown ${ }^{2}$, Susana S. Correia ${ }^{1}$ and José A. Esteban $^{1,2, *}$

${ }^{1}$ Department of Pharmacology and ${ }^{2}$ Neuroscience Program, University of Michigan Medical School, Ann Arbor, MI 48109

Running title: Analysis of Rab function in hippocampal neurons

*Correspondence: estebanj@umich.edu; phone: (734) 615-2686; FAX: (734) 7634450 


\begin{abstract}
Members of the Rab family of small GTPases are essential regulators of intracellular membrane sorting. Nevertheless, very little is known about the role of these proteins in the membrane trafficking processes that operate at synapses, and specifically, at postsynaptic terminals. These events include the activity-dependent exocytic and endocytic trafficking of AMPA-type glutamate receptors, which underlies long-lasting forms of synaptic plasticity such as long-term potentiation (LTP) and long-term depression (LTD). This chapter summarizes different experimental methods to address the role of Rab proteins in the trafficking of neurotransmitter receptors at postsynaptic terminals in the hippocampus. These techniques include: immunogold electron microscopy to ultrastructurally localize endogenous Rab proteins at synapses, molecular biology methods to express recombinant Rab proteins in hippocampal slice cultures, electrophysiological techniques to evaluate the role of Rab proteins in synaptic transmission, and confocal fluorescence imaging to monitor receptor trafficking at dendrites and spines and its dependence on Rab proteins.
\end{abstract}




\section{$\underline{\text { Introduction }}$}

The members of the Rab family of small GTPases are critical regulators of intracellular membrane trafficking and sorting in eukaryotes (Pfeffer, 2001; Zerial and McBride, 2001). This has been well established in a variety of cellular systems. However, very little is known of the functional role of Rab proteins in neurons, where polarized membrane trafficking is crucial for synaptic function and plasticity (Bredt and Nicoll, 2003; Wenthold et al., 2003; Ziv and Garner, 2004). The only notable exception is Rab3, which has been shown to modulate neurotransmitter release (Geppert et al., 1994; Geppert et al., 1997; Senyshyn et al., 1992) and is involved in some forms of presynaptic plasticity (Castillo et al., 1997; Castillo et al., 2002; Lonart et al., 1998). This chapter will focus on experimental approaches for the study of postsynaptic functions of Rab proteins in the endocytic and exocytic trafficking of AMPA-type glutamate receptors (AMPARs) at hippocampal synapses. By mediating AMPAR synaptic trafficking, some Rab proteins, namely Rab5, Rab8 and Rab11, have been shown to play central roles in synaptic plasticity (Brown et al., 2005; Gerges et al., 2004; Park et al., 2004).

\section{Ultrastructural studies of Rab proteins at synaptic terminals}

Previous work has shown that multiple Rab proteins are present in axonal and dendritic regions of hippocampal neurons (de Hoop et al., 1994; Fischer von Mollard et al., 1990; Huber et al., 1993). In order to determine the role of specific Rab proteins in local membrane trafficking at synapses, it is important to determine the presence and distribution of these proteins at synaptic terminals with high spatial resolution. This ultrastructural localization can be accomplished with postembedding immunogold electron microscopy (Brown et al., 2005; Gerges et al., 2004). 


\section{$\underline{\text { Method }}$}

Hippocampal tissue is fixed, dehydrated and processed for osmium-free postembedding immunogold labeling, as previously described (Phend et al., 1995). Thin sections are blocked with $2.5 \%$ BSA and $2.5 \%$ serum for 30 minutes at room temperature. They are then incubated with anti-Rab5 or anti-Rab8 antibodies (BD Biosciences) overnight, followed by incubation for 1 hour with secondary antibodies coupled to $10 \mathrm{~nm}$ gold particles (Electron Microscopy Sciences). Images are acquired with a transmission electron microscope using a digital camera. Quantification of gold particles and/or distance measurement is performed on digital images using image analysis software.

$\underline{\text { Analysis }}$

In order to interpret the synaptic distribution of endogenous Rab proteins, immunogold labeling can be binned according to its location within the synaptic terminal (see cartoon in Fig. 1). The following compartments are defined: presynaptic terminal (compartment " $A$ " in Fig. 1), intracellular space underneath the postsynaptic membrane (compartment "B"), postsynaptic density (PSD) (compartment "C"), and postsynaptic plasma membrane lateral to the postsynaptic density (compartment "D"). These quantifications are limited to immunogold particles found within $600 \mathrm{~nm}$ from the synaptic cleft. This experimental approach has been carried out for the synaptic distribution of endogenous Rab8 and Rab5 at CA1 excitatory synapses in the hippocampus. The analysis indicated that Rab8 accumulates at intracellular membranes within the spine (Gerges et al., 2004), whereas Rab5 is particularly abundant at the extrasynaptic plasma membrane (Brown et al., 2005).

The distance of each gold particle to the edge of the postsynaptic density along the plasma membrane is measured for further characterization of the lateral distribution of Rab 
proteins at synaptic and extrasynaptic cell surfaces. These distances can be computed using image analysis software, and presented as frequency histograms. This kind of analysis revealed that postsynaptic Rab5 is predominantly located outside of the postsynaptic density on lateral extrasynaptic membranes, roughly 100-300 $\mathrm{nm}$ away from the edge of the PSD (Brown et al., 2005).

\section{Cloning and expression of recombinant Rab proteins in hippocampal neurons}

In order to perturb Rab protein function in neurons, wild-type, dominant negative or constitutively active forms of these proteins can be overexpressed as recombinant proteins in organotypic hippocampal slice cultures. Rab protein coding sequences are cloned by standard RT-PCR techniques from rat brain mRNA preparations. Rab-GFP fusion proteins are made by in-frame ligation of the EGFP coding sequence (Clontech) with the amino termini of the Rab protein. Single amino acid substitutions that generate dominant negative (GDP-bound) and constitutively active (GTP-bound) mutants are well established. For example, S34N and Q79L produce dominant negative and constitutively active forms of Rab5, respectively ( $\mathrm{Li}$ and Stahl, 1993). T22N and Q67L produce equivalent phenotypes in Rab8 (Ren et al., 1996). The functionality of fluorescently-tagged Rab proteins has been described in multiple previous publications (see for instance (Sonnichsen et al., 2000)). Fusion proteins of Rab5 and Rab8 with a tandem-dimer variant of the red fluorescence protein DsRed (Campbell et al., 2002) have also been generated and tested in hippocampal neurons (Brown et al., 2005; Gerges et al., 2004).

All these constructs are recloned in pSinRep5 for expression using Sindbis virus (Schlesinger and Dubensky, 1999) or in mammalian expression plasmids for biolistic delivery (Lo et al., 1994). Recombinant proteins are expressed in organotypic hippocampal slice cultures 
(Gahwiler et al., 1997). Briefly, hippocampal slices are prepared from young rats (postnatal day 5 to 7) and placed in culture on semiporous membranes. After 4-5 days in culture, the recombinant gene is delivered into the slices. For expression of single proteins, the Sindbis virus is preferable. This is a replication-deficient, low-toxicity, neurotropic virus that allows the expression of recombinant proteins exclusively in neurons upon injection of the viral solution extracellularly in the desired area of the hippocampal slice. Co-expression of several proteins can be achieved with a Sindbis virus with an intervening IRES (see for instance (Hayashi et al., 2000)), or more typically, using the biolistic method with a combination of different plasmids bearing mammalian expression promoters, such as the CMV promoter. Either method leads to robust expression of the recombinant protein after 15 hour incubation (36 hour expression time is typically used when expressing recombinant AMPAR subunits).

\section{Electrophysiological studies of Rab protein function}

AMPA and NMDA receptors are the main ionotropic glutamate receptors at excitatory synapses in the hippocampus. Hence, the proper trafficking of these receptors is essential for synaptic function and plasticity. To study the role of Rab proteins in the targeting of AMPA and NMDA receptors into excitatory synapses, we express GFP-tagged dominant negative or constitutively active forms of these proteins in CA1 neurons from hippocampal slice cultures, and monitor AMPA and NMDA receptor-mediated synaptic transmission.

\section{Effect of recombinant Rab proteins on basal synaptic transmission}

Simultaneous double whole-cell recordings are obtained from nearby pairs of infected (expressing the recombinant protein) and uninfected (control) CA1 pyramidal neurons, under visual guidance using fluorescence and transmitted light illumination. The recording chamber is 
perfused with $119 \mathrm{mM} \mathrm{NaCl}, 2.5 \mathrm{mM} \mathrm{KCl}, 4 \mathrm{mM} \mathrm{CaCl}_{2}, 4 \mathrm{mM} \mathrm{MgCl} 2,26 \mathrm{mM} \mathrm{NaHCO}_{3}, 1 \mathrm{mM}$ $\mathrm{NaH}_{2} \mathrm{PO}_{4}, 11 \mathrm{mM}$ glucose, $0.1 \mathrm{mM}$ picrotoxin and $2 \mu \mathrm{M}$ 2-chloroadenosine, at $\mathrm{pH}$ 7.4, gassed with $5 \% \mathrm{CO}_{2} / 95 \% \mathrm{O}_{2}$ (2-chloroadenosine is used to reduce presynaptic function and, therefore, compensate for the enhanced connectivity of the slice cultures). Patch recording pipettes (3-6 $\mathrm{M} \Omega$ ) are filled with $115 \mathrm{mM}$ cesium methanesulfonate, $20 \mathrm{mM} \mathrm{CsCl}, 10 \mathrm{mM}$ HEPES, $2.5 \mathrm{mM}$ $\mathrm{MgCl}_{2}, 4 \mathrm{mM} \mathrm{Na}_{2} \mathrm{ATP}, 0.4 \mathrm{mM} \mathrm{Na} \mathrm{GTP}_{3}, 10 \mathrm{mM}$ sodium phosphocreatine and $0.6 \mathrm{mM}$ EGTA at pH 7.25. Voltage-clamp whole-cell recordings are carried out with multiclamp 700 amplifiers (Axon Instruments, Union City, California, USA). Synaptic responses are evoked with bipolar electrodes using single voltage pulses ( $200 \mu$ s, up to $20 \mathrm{~V})$. The stimulating electrodes are placed over Schaffer collateral fibers between $300 \mu \mathrm{m}$ and $500 \mu \mathrm{m}$ from the recorded cells. Synaptic AMPA receptor-mediated responses are measured at $-60 \mathrm{mV}$ and NMDA receptor-mediated responses at $+40 \mathrm{mV}$, at a latency when AMPA receptor responses have fully decayed (60 ms). Synaptic responses are averaged over 50-100 trials. This experimental configuration specifically addresses postsynaptic functions of Rab proteins, since the recombinant protein is always expressed in CA1 neurons and presynaptic stimulation is delivered at the Schaffer collaterals from CA3 neurons. This approach has been employed to demonstrate that Rab8, but not other exocytic Rab proteins such as Rab4 and Rab11, are required for the constitutive cycling of AMPARs at hippocampal synapses (Gerges et al., 2004). Similarly, we have shown that the endocytic protein Rab5 drives the removal of AMPARs from these synapses (Brown et al., 2005).

Synaptic plasticity (LTP, LTD)

Neuronal activity continuously remodels synaptic connectivity. This process, known as synaptic plasticity, is widely thought to be the cellular correlate of learning and memory. Some 
of the best-studied forms of synaptic plasticity are long-term potentiation (LTP) and long-term depression (LTD) in CA1 hippocampal synapses. The involvement of specific Rab proteins in these forms of synaptic plasticity can be addressed by expressing dominant negative forms of these proteins in organotypic hippocampal slice cultures. Synaptic plasticity is then induced under whole-cell configuration on neurons expressing the recombinant protein (introduced via infection or transfection, see above) or on control neurons. LTP is induced by pairing $0 \mathrm{mV}$ depolarization of the postsynaptic neuron with $3 \mathrm{~Hz}$ presynaptic stimulation (300 pulses). Baseline recordings before LTP induction should be limited to 2-5 minutes because critical factors required for LTP induction are quickly washed-out in whole-cell configuration. LTD is induced by pairing $1 \mathrm{~Hz}$ presynaptic stimulation (500 pulses) with moderate postsynaptic depolarization $(-40 \mathrm{mV})$. Using these protocols on CA1 hippocampal neurons expressing Rab8 or Rab5 dominant negative mutants, we have determined that Rab8 mediates the synaptic delivery of AMPARs during LTP (Gerges et al., 2004), whereas Rab5 function is required for AMPAR internalization upon LTD induction (Brown et al., 2005).

\section{Electrophysiological tagging}

AMPARs are tetrameric molecules (Greger et al., 2003; Tichelaar et al., 2004) composed of different combinations of GluR1 to GluR4 subunits (Hollmann and Heinemann, 1994). In hippocampus, most of AMPA receptors are composed of GluR1/GluR2 or GluR2/GluR3 subunits (Wenthold et al., 1996). These two populations reach synapses according to different pathways: GluR2/GluR3 AMPA receptors continuously cycle in and out of synapses in a manner that is independent from synaptic activity (Passafaro et al., 2001; Shi et al., 2001). In contrast, GluR1/GluR2 AMPA receptors are added into synapses in an activity-dependent manner during synaptic plasticity (Hayashi et al., 2000; Passafaro et al., 2001; Shi et al., 2001). These two 
pathways have been coined as constitutive and regulated, respectively (Malinow et al., 2000). On the other hand, activity-dependent removal of AMPARs during LTD seems to affect both populations of receptors (Beattie et al., 2000; Brown et al., 2005; Ehlers, 2000; Lee et al., 2004; Lin et al., 2000). Electrophysiological tagging is a powerful tool to monitor the presence of these distinct pools of receptors at the synapse, as described below.

Most endogenous AMPA receptors in the hippocampus display a linear current-voltage relation, that is, they conduct inward currents at negative membrane potentials, and outward currents at positive ones (see cartoon in Fig. 2A). This is dependent on the presence of an edited GluR2 subunit (arginine 607) in the receptor (Verdoorn et al., 1991). Overexpression of recombinant AMPAR subunits leads to the formation of homomeric channels that lack endogenous GluR2 subunits (Hayashi et al., 2000). These channels display inward rectification, that is, they conduct inward currents at negative membrane potentials, but no outward current at positive membrane potentials (Fig. 2B). This is due to the blockade of the channel by endogenous polyamines (Bowie and Mayer, 1995; Donevan and Rogawski, 1995; Kamboj et al., 1995). Thus, synaptic incorporation of homomeric recombinant receptors (either GluR1 or the unedited form of GluR2 -glutamine 607) increases inward rectification of synaptic responses (Fig. 2C). This effect can be quantified as an increase in the ratio of AMPAR-mediated responses at $-60 \mathrm{mV}$ versus $+40 \mathrm{mV}$ (rectification index). GluR1-GFP homomeric receptors behave like GluR1/GluR2 receptors, i.e. they are delivered at synapses in an activity-dependent manner. Therefore, GluR1-GFP homomers can be used as reporters for the regulated addition of AMPARs during LTP. In contrast, GluR2-GFP homomers mimic GluR2/GluR3 receptor trafficking, and therefore, they can be used as reporters for the constitutive synaptic cycling of AMPARs (Shi et al., 2001). 
To test the role of Rab proteins in the synaptic delivery or removal of specific AMPA receptor populations, the Rab protein under consideration is co-expressed with either GluR1GFP or GluR2Q607-GFP using the biolistic gene delivery method (see above). Whole-cell voltage-clamp recordings of synaptic responses are then obtained at $-60 \mathrm{mV}$ and $+40 \mathrm{mV}$ from transfected neurons expressing the receptor alone, or the receptor plus the Rab protein, or from control (untransfected) neurons. To isolate AMPAR-mediated responses at $+40 \mathrm{mV}, 0.1 \mathrm{mM}$ of the NMDA receptor antagonist AP5 is added to the perfusion solution. In addition, the intracellular solution in the recording pipette is supplemented with $0.1 \mathrm{mM}$ spermine, to prevent wash-out of the endogenous polyamines required for AMPAR inward rectification. The rectification index of AMPAR-mediated synaptic transmission is then calculated as the ratio between the responses at $-60 \mathrm{mV}$ and $+40 \mathrm{mV}$. This method has allowed us to determine that Rab5 and Rab8 mediate, respectively, the endocytic and exocytic trafficking of both GluR1 and GluR2 populations of AMPARs at synapses (Brown et al., 2005; Gerges et al., 2004).

\section{Confocal fluorescence imaging of Rab protein function in AMPA receptor trafficking at}

\section{dendrites and spines}

Method

To address the role of Rab proteins in the trafficking of AMPARs along dendrites and their insertion into dendritic spines, GFP-tagged AMPAR subunits (either GluR1 or GluR2) are coexpressed with Rab proteins tagged with a red fluorescence protein (RFP; see above). These proteins are co-transfected in rat hippocampal organotypic slices using the biolistic transfection system. After 1.5 days of expression, organotypic slices are processed for surface immunostaining of the GFP-tagged receptors. Briefly, slices are fixed with $4 \%$ 
paraformaldehyde $/ 4 \%$ sucrose in PBS for 2 hours at $4{ }^{\circ} \mathrm{C}$, and then blocked in $2 \%$ serum for 1 hour at room temperature. Slices are then successively incubated with anti-GFP antibody (Roche) overnight at $4{ }^{\circ} \mathrm{C}$, with biotinylated anti-mouse antibody for 1 hour at room temperature, and with streptavidin coupled to Cy5 (Molecular Probes) for 1 hour at room temperature. All these incubations are done in the absence of detergent, and therefore, the immunolabeling is restricted to GFP-tagged AMPARs exposed to the cell surface. Confocal fluorescence images from the GFP, RFP and Cy5 channels are then collected using an Olympus FV500 confocal microscope with a 60x oil immersion lens. Digital images are acquired using the FluoView software and are reconstructed and analyzed using Image $\mathrm{J}$ software (http://rsb.info.nih.gov/ij/). This experimental approach allows us to separately monitor the recombinant AMPAR receptor (GFP channel), its surface expression (Cy5 channel) and the co-expression of the Rab protein (RFP channel).

\section{Analysis of large-scale dendritic trafficking}

The efficiency of AMPAR transport along dendrites can be evaluated by quantifying GFP fluorescence intensity along the primary apical dendrite from neurons expressing a GFP-tagged AMPAR subunit. This is obtained by drawing a pixel-wide line along the dendrite and plotting its GFP fluorescence profile (see example in Fig. 3A). After background subtraction, the value of fluorescence intensity in each pixel is normalized to the maximum fluorescence at the soma of the neuron. This normalization accounts for variability in expression levels of the recombinant proteins. The normalized fluorescence intensity is then plotted as a function of the distance from the cell body (Fig 3B). The effect of a recombinant Rab protein on AMPAR dendritic trafficking is then evaluated by comparing the fluorescence profile of the GFP-tagged receptor with or without co-expression of the RFP-tagged Rab protein. 


\section{Analysis of local dendritic spine trafficking}

To determine AMPA receptor partition between spines and dendrites, the GFP fluorescence intensity at these two compartments is quantified using a line plot that crosses the spine head and its adjacent dendritic shaft (see Fig. 4A, left). The amount of GFP-tagged AMPAR at each compartment is then estimated from the corresponding peaks of GFP fluorescence after background subtraction (Fig. 4B, left).

To determine the surface expression of recombinant AMPA receptors, GFP (total receptor; Fig. 4A, left) and Cy5 (surface receptor; Fig. 4A, right) fluorescence intensities are quantified using line plots, as described above. Surface ratios are then calculated for spine and dendrites by dividing Cy5 and GFP fluorescence peaks after background subtraction (Fig. 4B). This method is internally normalized for immunostaining variability, since the Cy5/GFP ratios are always acquired in pairs of spine and adjacent dendrite. Additionally, spine-dendrite pairs are exclusively selected from the GFP channel, avoiding any bias with respect to their surface immunostaining.

This analysis is carried out from neurons expressing a GFP-tagged AMPAR subunit alone, or from neurons co-expressing GFP-AMPARs together with RFP-tagged Rab proteins. In order to determine whether coexpression with a recombinant Rab protein alters receptor distribution between spines and dendrites, we calculate spine/dendrite ratios of either total receptor (GFP channel) or surface ratios (GFP/Cy5), for each pair of spine and dendritic shaft. For instance, in the case of the surface expression, a collection of spine/dendrite ratios would be obtained as:

$$
\begin{aligned}
& \text { Ratio }_{1}=(\mathrm{Cy} 5 / \mathrm{GFP}) \text { spine }_{1} /(\mathrm{Cy} 5 / \mathrm{GFP}) \text { dendrite }_{1} \\
& \text { Ratio }_{2}=(\mathrm{Cy} 5 / \mathrm{GFP}) \text { spine }_{2} /(\mathrm{Cy} 5 / \mathrm{GFP}) \text { dendrite }_{2}
\end{aligned}
$$


etc...

This collection of values can then be compared with or without co-expressed Rab protein using cumulative distributions and two-sample Kolmogorov-Smirnov tests. This experimental approach has allowed us to determine that Rab5 and Rab8 are involved, respectively, in the endocytic and exocytic trafficking of AMPARs within the spine, but not in their transport between dendritic shafts and spines (Brown et al., 2005; Gerges et al., 2004). 


\section{$\underline{\text { Acknowledgments }}$}

We thank Donald Backos for expert technical assistance with cloning and expression of recombinant proteins in organotypic hippocampal slice cultures. We also thank Kathryn Weiss, Dorothy Sorenson and Chris Edwards for their help with immunogold electron microscopy. This work was supported by the National Institute of Mental Health (grant MH070417 to J.A.E. and grant F31-MH070205 to T.C.B.), the National Alliance for research on Schizophrenia and Depression (J.A.E.), the Alzheimer's Association (J.A.E.) and the Fundação para a Ciência e a Tecnologia (S.S.C.). 


\section{REFERENCES}

Beattie, E. C., Carroll, R. C., Yu, X., Morishita, W., Yasuda, H., von Zastrow, M., and Malenka, R. C. (2000). Regulation of AMPA receptor endocytosis by a signaling mechanism shared with LTD. Nat Neurosci 3, 1291-300.

Bowie, D., and Mayer, M. L. (1995). Inward rectification of both AMPA and kainate subtype glutamate receptors generated by polyamine-mediated ion channel block. Neuron 15, 453-62.

Bredt, D. S., and Nicoll, R. A. (2003). AMPA receptor trafficking at excitatory synapses. Neuron 40, 361-79.

Brown, T. C., Tran, I. C., Backos, D. S., and Esteban, J. A. (2005). NMDA receptor-dependent activation of the small GTPase Rab5 drives the removal of synaptic AMPA receptors during hippocampal LTD. Neuron 45, 81-94.

Campbell, R. E., Tour, O., Palmer, A. E., Steinbach, P. A., Baird, G. S., Zacharias, D. A., and Tsien, R. Y. (2002). A monomeric red fluorescent protein. Proc Natl Acad Sci U S A 99, 7877-82.

Castillo, P. E., Janz, R., Sudhof, T. C., Tzounopoulos, T., Malenka, R. C., and Nicoll, R. A. (1997). Rab3A is essential for mossy fibre long-term potentiation in the hippocampus. Nature 388, 590-3.

Castillo, P. E., Schoch, S., Schmitz, F., Sudhof, T. C., and Malenka, R. C. (2002). RIM1alpha is required for presynaptic long-term potentiation. Nature 415, 327-30.

de Hoop, M. J., Huber, L. A., Stenmark, H., Williamson, E., Zerial, M., Parton, R. G., and Dotti, C. G. (1994). The involvement of the small GTP-binding protein Rab5a in neuronal endocytosis. Neuron 13, 11-22. 
Donevan, S. D., and Rogawski, M. A. (1995). Intracellular polyamines mediate inward rectification of $\mathrm{Ca}(2+)$-permeable alpha-amino-3-hydroxy-5-methyl-4-isoxazolepropionic acid receptors. Proc Natl Acad Sci U S A 92, 9298-302.

Ehlers, M. D. (2000). Reinsertion or degradation of AMPA receptors determined by activitydependent endocytic sorting. Neuron 28, 511-25.

Fischer von Mollard, G., Mignery, G. A., Baumert, M., Perin, M. S., Hanson, T. J., Burger, P. M., Jahn, R., and Sudhof, T. C. (1990). rab3 is a small GTP-binding protein exclusively localized to synaptic vesicles. Proc Natl Acad Sci U S A 87, 1988-92.

Gahwiler, B. H., Capogna, M., Debanne, D., McKinney, R. A., and Thompson, S. M. (1997). Organotypic slice cultures: a technique has come of age. Trends Neurosci 20, 471-7.

Geppert, M., Bolshakov, V. Y., Siegelbaum, S. A., Takei, K., De Camilli, P., Hammer, R. E., and Sudhof, T. C. (1994). The role of Rab3A in neurotransmitter release. Nature 369, 493-7.

Geppert, M., Goda, Y., Stevens, C. F., and Sudhof, T. C. (1997). The small GTP-binding protein Rab3A regulates a late step in synaptic vesicle fusion. Nature 387, 810-4.

Gerges, N. Z., Backos, D. S., and Esteban, J. A. (2004). Local control of AMPA receptor trafficking at the postsynaptic terminal by a small GTPase of the Rab family. J Biol Chem 279, $43870-8$.

Greger, I. H., Khatri, L., Kong, X., and Ziff, E. B. (2003). AMPA receptor tetramerization is mediated by Q/R editing. Neuron 40, 763-74.

Hayashi, Y., Shi, S. H., Esteban, J. A., Piccini, A., Poncer, J. C., and Malinow, R. (2000). Driving AMPA receptors into synapses by LTP and CaMKII: requirement for GluR1 and PDZ domain interaction. Science 287, 2262-7. 
Hollmann, M., and Heinemann, S. (1994). Cloned glutamate receptors. Annu Rev Neurosci 17, 31-108.

Huber, L. A., de Hoop, M. J., Dupree, P., Zerial, M., Simons, K., and Dotti, C. (1993). Protein transport to the dendritic plasma membrane of cultured neurons is regulated by rab8p. $J$ Cell Biol 123, 47-55.

Kamboj, S. K., Swanson, G. T., and Cull-Candy, S. G. (1995). Intracellular spermine confers rectification on rat calcium-permeable AMPA and kainate receptors. J Physiol 486 ( Pt 2), 297-303.

Lee, S. H., Simonetta, A., and Sheng, M. (2004). Subunit rules governing the sorting of internalized AMPA receptors in hippocampal neurons. Neuron 43, 221-36.

Li, G., and Stahl, P. D. (1993). Structure-function relationship of the small GTPase rab5. J Biol Chem 268, 24475-80.

Lin, J. W., Ju, W., Foster, K., Lee, S. H., Ahmadian, G., Wyszynski, M., Wang, Y. T., and Sheng, M. (2000). Distinct molecular mechanisms and divergent endocytotic pathways of AMPA receptor internalization. Nat Neurosci 3, 1282-90.

Lo, D. C., McAllister, A. K., and Katz, L. C. (1994). Neuronal transfection in brain slices using particle-mediated gene transfer. Neuron 13, 1263-8.

Lonart, G., Janz, R., Johnson, K. M., and Sudhof, T. C. (1998). Mechanism of action of rab3A in mossy fiber LTP. Neuron 21, 1141-50.

Malinow, R., Mainen, Z. F., and Hayashi, Y. (2000). LTP mechanisms: from silence to four-lane traffic. Curr Opin Neurobiol 10, 352-7.

Park, M., Penick, E. C., Edwards, J. G., Kauer, J. A., and Ehlers, M. D. (2004). Recycling endosomes supply AMPA receptors for LTP. Science 305, 1972-5. 
Passafaro, M., Piech, V., and Sheng, M. (2001). Subunit-specific temporal and spatial patterns of AMPA receptor exocytosis in hippocampal neurons. Nat Neurosci 4, 917-26.

Pfeffer, S. R. (2001). Rab GTPases: specifying and deciphering organelle identity and function. Trends Cell Biol 11, 487-91.

Phend, K. D., Rustioni, A., and Weinberg, R. J. (1995). An osmium-free method of epon embedment that preserves both ultrastructure and antigenicity for post-embedding immunocytochemistry. $J$ Histochem Cytochem 43, 283-92.

Ren, M., Zeng, J., De Lemos-Chiarandini, C., Rosenfeld, M., Adesnik, M., and Sabatini, D. D. (1996). In its active form, the GTP-binding protein rab8 interacts with a stress-activated protein kinase. Proc Natl Acad Sci US A 93, 5151-5.

Schlesinger, S., and Dubensky, T. W. (1999). Alphavirus vectors for gene expression and vaccines. Curr Opin Biotechnol 10, 434-9.

Senyshyn, J., Balch, W. E., and Holz, R. W. (1992). Synthetic peptides of the effector-binding domain of rab enhance secretion from digitonin-permeabilized chromaffin cells. FEBS Lett 309, 41-6.

Shi, S., Hayashi, Y., Esteban, J. A., and Malinow, R. (2001). Subunit-specific rules governing AMPA receptor trafficking to synapses in hippocampal pyramidal neurons. Cell 105, 331-43.

Sonnichsen, B., De Renzis, S., Nielsen, E., Rietdorf, J., and Zerial, M. (2000). Distinct membrane domains on endosomes in the recycling pathway visualized by multicolor imaging of Rab4, Rab5, and Rab11. J Cell Biol 149, 901-14.

Tichelaar, W., Safferling, M., Keinanen, K., Stark, H., and Madden, D. R. (2004). The Threedimensional Structure of an Ionotropic Glutamate Receptor Reveals a Dimer-of-dimers Assembly. J Mol Biol 344, 435-42. 
Verdoorn, T. A., Burnashev, N., Monyer, H., Seeburg, P. H., and Sakmann, B. (1991). Structural determinants of ion flow through recombinant glutamate receptor channels. Science 252, $1715-8$.

Wenthold, R. J., Petralia, R. S., Blahos, J., II, and Niedzielski, A. S. (1996). Evidence for multiple AMPA receptor complexes in hippocampal CA1/CA2 neurons. J Neurosci 16, 1982-9.

Wenthold, R. J., Prybylowski, K., Standley, S., Sans, N., and Petralia, R. S. (2003). Trafficking of NMDA receptors. Annu Rev Pharmacol Toxicol 43, 335-58.

Zerial, M., and McBride, H. (2001). Rab proteins as membrane organizers. Nat Rev Mol Cell Biol 2, 107-17.

Ziv, N. E., and Garner, C. C. (2004). Cellular and molecular mechanisms of presynaptic assembly. Nat Rev Neurosci 5, 385-99. 


\section{FIGURE LEGENDS}

Figure 1. Schematic representation of a synaptic terminal with the different compartments defined for quantification of immunogold labeling. A. Presynaptic compartment. B. Intracellular postsynaptic compartment. C. Postsynaptic density. D. Extrasynaptic plasma membrane lateral from the postsynaptic density.

Figure 2. Cartoon representing inward rectification of recombinant AMPA receptors and their use as an "electrophysiological tag". A. Endogenous (GluR2-containing) AMPA receptors conduct inward and outward currents at negative and positive membrane potentials, respectively. B. Recombinant AMPA receptors form homomeric channels lacking endogenous GluR2. Hence, they conduct only inward currents (inward rectification). C. Synapses containing both endogenous and recombinant receptors display an increased ratio of inward to outward currents (rectification index) because both kinds of receptors contribute to the inward current, whereas only endogenous receptors conduct outward currents. See further explanation in the main text.

Figure 3. Quantitative analysis of the large-scale distribution of GFP-tagged receptors along dendrites. A. Representative example of a CA1 hippocampal neuron expressing GluR2GFP. White line represents a pixel-wide trajectory along the main apical dendrite, from which GFP fluorescence intensity is quantified. The line is shifted downward from its original position on the dendrite to facilitate visualization. B. Quantification of GFP-fluorescence intensity along 
the line shown in A. Fluorescence values are background-subtracted and normalized to the maximum at the cell soma.

Figure 4. Quantitative analysis of the local trafficking of GFP-tagged receptors at dendritic spines. A. Representative confocal image of a spine and the adjacent dendritic shaft from a neuron expressing GluR2-GFP. GFP fluorescence signal (left) represents total receptor distribution. Cy5 signal (right) is obtained by immunostaining with anti-GFP antibodies under non-permeabilized conditions, and therefore, it represents the fraction of receptor exposed to the cell surface. Scale bar: $1 \mu \mathrm{m}$. B. Quantification of fluorescence intensity of the GFP (left) and Cy5 (right) signals along the white lines shown in A. The peaks of fluorescence intensity at the dendritic shaft and the spine head after background subtraction (dotted lines) are used to estimate total receptor distribution (GFP) and surface ratio (Cy5/GFP) at dendrites and spines. 
Presynaptic

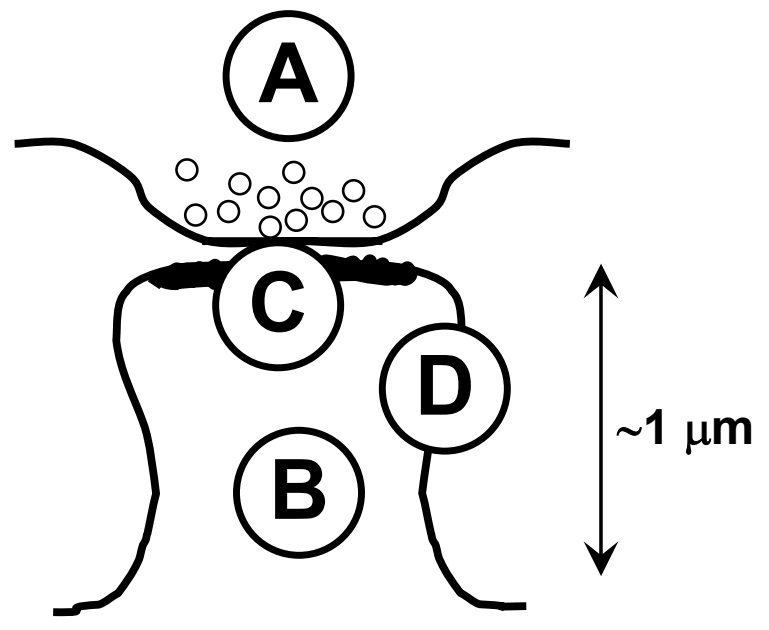

Postsynaptic

Figure 1 
A

Endogenous
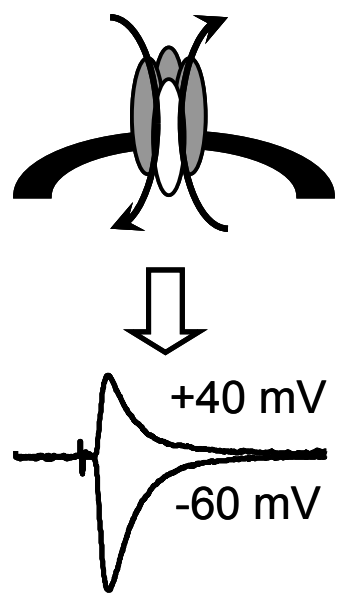

B

Homomeric recombinant
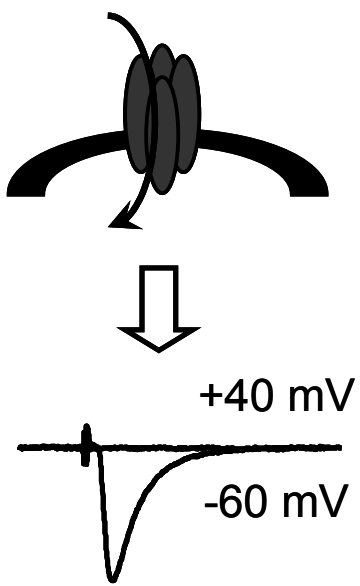

C

Homomeric recombinant

+ Endogenous

GluR2 GluR1, 3 or $4 \bigcap$ GluR-GFP

Figure 2 


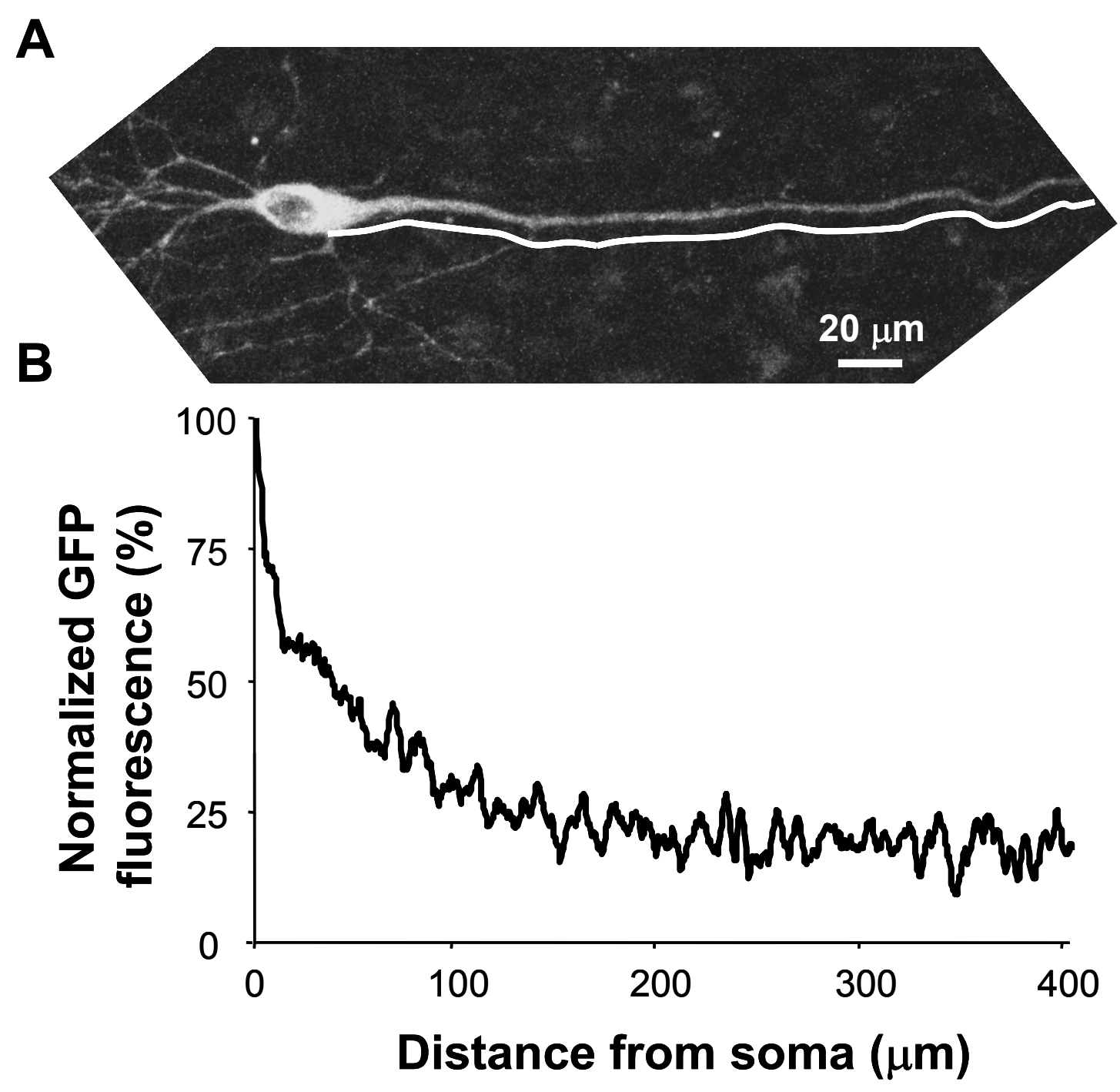

Figure 3 
A

Surface anti-GFP

\section{GluR2-GFP}

(Cy5)


Figure 4 